\title{
Comprehending Unpredictable/Random Behaviour by Applying Environment Performance Indicators in a Real Milieu
}

\author{
Khalid A. Fakeeh, PhD \\ King Abdullaziz University \\ Jeddah, Saudi Arabia
}

\begin{abstract}
The purpose of this study is to propose a study into understanding unpredictable behaviour by applying environment performance indicators in a real environment. From the literature review, it is evident that a simulation model should be created that consists of environmental variables. This study is useful to managers and IT staff of a business to see how they can improve business processes.
\end{abstract}

\section{Keywords}

Business Process Modelling, Environment Performance Indicators, Simulation Modelling

\section{INTRODUCTION}

Business process modelling (BPM) represents a current process of a business for analysing and improving its performance. 'Successful business process modelling relies on an adequate view of the nature of business processes [11] According to [11], to ensure success businesses need to identify the essence of a business process. In the case of this research paper, the essence represents unpredictable behaviour from environment performance indicators. It is unpredictable as there is pressure from the environment. Other environment performance indicators that causes uncertainty in a business are resources and waste output [7].

\begin{tabular}{|l|l|l|l|}
\hline $\begin{array}{l}\text { Environmental } \\
\text { impact }\end{array}$ & \multicolumn{1}{|c|}{$\begin{array}{c}\text { Absolute } \\
\text { data }\end{array}$} & \multicolumn{1}{c|}{$\begin{array}{c}\text { Normalized } \\
\text { data }\end{array}$} & \multicolumn{1}{c|}{ Trend data } \\
\hline $\begin{array}{l}\text { Greenhouse } \\
\text { gas emissions }\end{array}$ & $\begin{array}{l}\text { Total annual } \\
\text { carbon dioxide } \\
\text { emissions }\end{array}$ & $\begin{array}{l}\text { Carbon dioxide } \\
\text { emissions per } \\
\text { employee, per } \\
\text { unit of output, } \\
\text { etc. }\end{array}$ & $\begin{array}{l}\text { Total emissions of } \\
\text { carbon dioxide or } \\
\text { emissions per } \\
\text { employee compared } \\
\text { with previous years }\end{array}$ \\
\hline $\begin{array}{l}\text { Water } \\
\text { consumption }\end{array}$ & $\begin{array}{l}\text { Total annual } \\
\text { water } \\
\text { consumption }\end{array}$ & $\begin{array}{l}\text { Water } \\
\text { consumption } \\
\text { per employee, } \\
\text { per unit of } \\
\text { output, etc. }\end{array}$ & $\begin{array}{l}\text { Total consumption } \\
\text { or consumption per } \\
\text { employee compared } \\
\text { with previous years }\end{array}$ \\
\hline Waste output & $\begin{array}{l}\text { Total annual } \\
\text { waste output } \\
\text { in tonnes }\end{array}$ & $\begin{array}{l}\text { Waste output } \\
\text { per employee, } \\
\text { or per unit of } \\
\text { output, etc. }\end{array}$ & $\begin{array}{l}\text { Total waste or } \\
\text { waste per employee } \\
\text { compared with } \\
\text { previous years }\end{array}$ \\
\hline
\end{tabular}

Figure 2: Indicators relevant to all organization [7] 


\begin{tabular}{|c|c|c|}
\hline $\begin{array}{l}\text { Environmental } \\
\text { impact }\end{array}$ & Indicator & Comment \\
\hline $\begin{array}{l}\text { Airborne } \\
\text { Emissions(other } \\
\text { than greenhouse } \\
\text { gases) }\end{array}$ & $\begin{array}{l}\text { 1. Total tonnes of ozone } \\
\text { depleting gases, } \mathrm{SO}_{2}, \mathrm{NO}_{2}, \\
\text { particulates }\end{array}$ & $\begin{array}{l}\text { These indicators are } \\
\text { only relevant when } \\
\text { such gases are being } \\
\text { emitted. }\end{array}$ \\
\hline $\begin{array}{l}\text { Resource use } \\
\text { and raw } \\
\text { materials }\end{array}$ & $\begin{array}{l}\text { 1. Total tonnes of raw } \\
\text { materials used }\end{array}$ & $\begin{array}{l}\text { Normalized data that } \\
\text { relate tonnes of raw } \\
\text { materials input to } \\
\text { tonnes or units of } \\
\text { output are normally } \\
\text { used. }\end{array}$ \\
\hline Transport & $\begin{array}{l}\text { 1. Total fuel consumed } \\
\text { 2. } \mathrm{CO}_{2} \text { emissions per } 1000 \\
\mathrm{~km} \text { traveled } \\
\text { 3. Vehicle fill per cent, and } \\
\text { empty running per cent } \\
\text { 4. Employee kilometers } \\
\text { covered on business travel } \\
\text { (road/air/rail) } \\
\text { 5. Proportion of employees } \\
\text { traveling alone by car when } \\
\text { commuting }\end{array}$ & $\begin{array}{l}\text { For some companies, } \\
\text { employee commuting } \\
\text { may be a cause of } \\
\text { significant } \\
\text { environmental } \\
\text { impact. }\end{array}$ \\
\hline Energy & $\begin{array}{l}\text { 1. } \mathrm{CO}_{2} \text { emissions by energy } \\
\text { type or major use } \\
\text { 2. Consumption by type }\end{array}$ & $\begin{array}{l}\text { You may also want to } \\
\text { supplement the } \\
\text { information on total } \\
\mathrm{CO}_{2} \text { emissions from } \\
\text { energy use by } \\
\text { breaking it down by } \\
\text { types or uses. }\end{array}$ \\
\hline $\begin{array}{l}\text { Water } \\
\text { Polluta }\end{array}$ & $\begin{array}{l}\text { 1. Total discharge of effluent } \\
\mathrm{m}^{3} \\
\text { 2. } \mathrm{m}^{3} \text { effluent per tonne of } \\
\text { product }\end{array}$ & $\begin{array}{l}\text { This may include } \\
\text { chemical oxygen } \\
\text { demanding emissions } \\
\text { (COD), biochemical } \\
\text { oxygen demanding } \\
\text { emissions (BOD), } \\
\text { particulates or other } \\
\text { materials. }\end{array}$ \\
\hline $\begin{array}{l}\text { Hazardous } \\
\text { Waste }\end{array}$ & $\begin{array}{l}\text { 1. Total tonnes of hazardous } \\
\text { waste generated by type }\end{array}$ & $\begin{array}{l}\text { If your organization } \\
\text { produces specific } \\
\text { waste substances you } \\
\text { may want to quantify } \\
\text { these separately. }\end{array}$ \\
\hline
\end{tabular}

Figure 3: Indicators relevant to certain organizations [7]

Two themes this research paper aims to identify are simulation modelling and the procedure for the business modelling framework. 


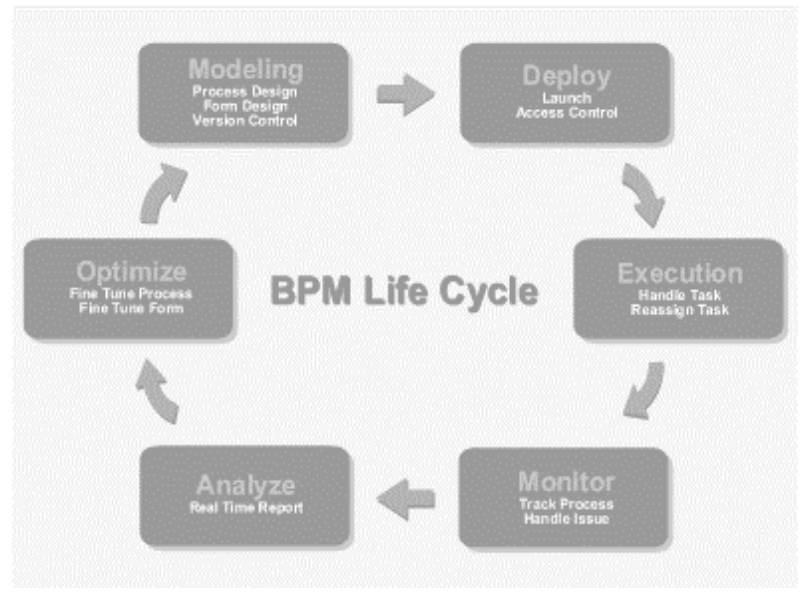

Figure 1: Business Process Modelling Life Cycle

\section{The objectives of this study}

The objective of this study is to understand the concept of understanding unpredictable behaviour by applying environment performance indicators in a real environment.

\section{The purpose of this study}

The purpose of this study contributes to practice as managers and IT staff are able to analyse business processes. By implementing a simulation model, improvements can be made to enhance performance.

The structure of this research paper begins with the introduction which highlights the objectives and purpose of this study. Next, is the literature review which reviews studies on simulation modelling, the importance of selecting the right model and customer oriented business process modelling. This is followed by the methodology which proposes methods to use when deciding on which model to apply and also the framework to structure the model. Finally, the conclusion summarizes the aim of this research paper and identifies the limitations and recommendations for future research.

\section{LITERATURE REVIEW}

One of the themes of this literature review will consist of a simulation modelling environment where a simulation can be created to predict the impact of environmental performance indicators in a real environment that possesses uncertainty. [2], conducted a study that represents business process modelling as a problem that is resolved by understanding its social and knowledge activity. Their methodology consisted of designing a knowledge centred framework as 'a systematic general problem-resolution methodology' [2]. A need for understanding behaviour in a real environment is expressed by [2], to better understand business process models that can improve organizational efficiency and quality. However, criticism is found in such modelling for its reliability and accuracy. [2]. The complexity of understanding the uncertainty of environmental factors include knowledge and social activity which can be made difficult by the organizations' strategy. Their study identifies stakeholders such as business partners, customers and suppliers to be part of the complication. Because of this, 'reductionist process management approaches cannot deal with this complexity effectively and are always likely to fail because they lack a holistic view [1]. The purpose of this research paper is to acknowledge the need for applying environment performance indicators to a real environment and it is argumentative that organizations rely on 'generic modelling formalisms [2], which does not contribute to quantitative assessment. [2], continue to express the limitations of not using a knowledge centered framework and the role of information and communication technologies and methodologies in overcoming them. They again identify a limitation of studies that investigate the collaboration process between social and knowledge simulation models. Therefore, their study developed an 'enhanced process modelling construct (EPMC)' with reference to Giddens, 1984 structuration theory. The aim of the EPMC is to integrate a collaborative modelling process. The critical review of knowledge carried out will be the process of transforming knowledge to new information and results in the re-organization of the knowledge base. To review the robustness of the model requires a quantitative algorithm which rectifies problems. The framework they propose includes a group model building by selection and augmentation (G-MoBSA) methodology as 'a systemic general problem-resolution' methodology. [2]. The purpose of the framework is to again understand what the stakeholders view the process to observe. The model is able to run simulations in a simulation modelling environment and outputs are relayed to stakeholders. The limitation of their study is that the results of the quantitative algorithm is only indicative and further research needs to be undertaken. They conclude by stressing the modelling process requires interaction from stakeholders and their perspectives to contribute knowledge. The framework they proposed is only a pilot operation and there is a research gap to implement in a real setting. Another limitation is the framework, 'depends heavily on the availability and the technical abilities of the technical facilitator [2]. [3], communicates that an understanding of the need of a business process model is significant; to better understand the business process. [3], study looks at presenting the main business modelling techniques. As there are a vast number of literature on business process modelling [3], makes it less tedious by developing a framework consisting of the purpose of the techniques. To get a closer understanding of BPM, techniques should be discussed so this research paper can understand why organizations should consider unpredictable behaviour and the impact of it in a real environment that includes uncertainty. [3], highlights the importance of creating models in order to figure out systems. The review aims to give a more detailed specification of the tools and techniques presented in [9] study. 'It is important to identify the uses or purposes of the models when undertaking modelling of any kind.' This research paper will follow this perspective by initially constructing the purpose and implementing unpredictable behaviour into the model. Depending on the purpose of the model, in particular BPM needs to be analysed, controlled and monitored. Some of the common BPM models pointed out by [3], are Total Quality Management, continuous Process Improvement and Organisational Transformation. [3], proposed framework first highlights the purpose of the model as a summary of BPM techniques. Some of the reviews are flow chart, Gantt chart, object oriented methods and rich pictures. The purpose of the framework was to explain the techniques and hence indicating which BPM tools should be 
used in any given situation. The framework is useful to senior management of organizations as a way of developing their business strategy to improve processes. The models can be used for analysis of business process and to facilitate process agility. The limitations of [3], study is the criteria in which the models were assessed, may not be suitable for the purpose of classifying organizations needed for BPM. Also, a greater depth of information is needed of a tool to help select which is most accurate for a business process. [14], study examines customer oriented business process modelling. It creates a new structure framework which combines business process and customer orientation through statistical analysis for 'business process simulation modelling,' [14]. The reason to review this literature study is for its use of business process simulation modelling. As this research paper aims to understand uncertainty in a real environment, simulation modelling allows environment performance indicators to be implemented into the simulation to assess its impact. [14], highlight the importance of inputting the variables; in the case of their research it is customer requirements. Alternatively, for this research paper it will be performance environment indicators. They use statistical distributions to finalise the simulation model. In a real environment it is necessary to identify the constraints and [14], study identifies the constraints as customers and stakeholder preferences. To support the structured business process, they apply systemic techniques such as Quality Function Deployment (QFD). This tool is used for the transformation of customer needs to engineering parameters and customer needs. The benefit of using QFD its capability 'to analyse more generally customers' expectations on services and other characteristics associated to business process systems.' [14]. It is able to aid in viewing the performance of the business process holistically. [14], discover that difficulty is caused by the ambiguity of the ordinary QFD so an extended version of QFD is presented. This next process for the QFD analysis is to identify the technical features of the product. In this step, cost and time disseminations for inputs and outputs are taken into account. The purpose of the simulation is to assess business process performance against customer requirements. The benefit of their paper is to develop simulation experiments that they can quickly refer to the correlation table. In their study, scores in the table reveal the variables have some impact and should be varied in simulation experiments. After performing the simulation experiments, conclusions can be drawn. Lastly, comparison is undertaken for results of the simulation in terms of customer preferences for their study and the performance of the business process model. [14], express the importance of using statistical analysis for the modelling. As mentioned before, applying statistics to modelling is important as it allows for analysis, drawing conclusions and evaluating the robustness of a model. The limitation of their paper is that there is not enough detailed analysis and they mention theories of queuing models and discrete systems are needed to improve accuracy. As the paper focusses on laying the foundation of 'systematic procedure in business process analysis and redesign,' [14], there is a need for further research that incorporates more dynamic simulation.

\section{METHODOLOGY}

As this research paper aims to understand unpredictable behaviour environmental indicators will need to be applied and implemented into the BPM. Therefore, a simulation model will be used. The purpose of this research paper is to understand unpredictable behaviour by applying environment performance indicators in a real setting. As passive models do not allow changes to take place in a model, the model proposed in this research paper will need to be active to deal with changes. This research paper focusses on two main research questions to explore. Firstly, from reviewing the literature, it is important to clarify the purpose of building a simulation model. Secondly, to create a simulation model that incorporates unpredictable behaviour such as environmental indicators. Lastly, to draw conclusions on how this affects the performance of the model. Upon reflection of the aims and objectives of the research, this study is predictive as it hypothesizes future likelihoods based on analysing available information [12]. As the research aim is to incorporate environmental performance indicators this research will follow a quantitative approach. Using a quantitative approach, 'provides summaries of data that support generalisations about the phenomenon under study' [13]. To achieve this, 'quantitative research usually involves few variables... and employs prescribed procedures to ensure validity and reliability' [13] reinforcing the accuracy of results. In addition, comparisons can be utilized with future similar studies by analysing quantitative data. Consequently, comparisons of findings can be of interest to researchers for future study as, 'quantitative methods allow us to summarize vast sources of information and facilitate comparisons across categories and over time.' [10]. Quantitative research can allow for greater objectivity and accuracy of results. Generally, quantitative methods are designed to provide summaries of data that support generalisations about the phenomenon under study. In order to accomplish this, quantitative...employs prescribed procedures to ensure validity and reliability [13]. However, there are limitations with only using a quantitative approach. Results may be limited to numerical summarisations rather than detailed reports. Moreover, the researcher may lead to structural bias and ambiguous data. However, the advantages of using quantitative data is that it saves time. Therefore, a quantitative approach will be applied. The methodology will consist of a deductive approach by analysing statistical data in quantitative research. [6], explain that 'according to positivists, laws provide the basis of explanation' [6]. In light of this, the deductive methodology is most suitable as conclusions derived indicate relationships between variables, 'Explanation consists of establishing casual relationships between the variables by establishing casual laws and linking them to a deductive...theory' [6]. The research philosophy consists of a positivistic approach by creating links and relationships between variables and implementing them into practice 'a positivistic methodology whereby a sample of subjects is drawn from a population and studied to make inferences about the population' [6]. This research consists of 'a cross-sectional design ....in order to collect quantitative data... which are then examined to detect patterns of association' [5].

\section{METHOD}

The structure follows five steps:

1. Creating a business process model and converting it into a simulation model 
2. Determine requirements for the model

3. Use statistical analysis to model distributions.

4. Select variables to be input into the simulation experiments and run them.

5. Make comparisons of the simulation results.

As [4] explain, an iterative process of modelling will be used as empirical statistical modelling uses past and present data to make statistical inferences. [14], explains that if no data is available then preferences may be based on past data and experiences.

When the simulation has been performed, comparisons of the data can be made to derive conclusions on desirable and actual performance. The analysis of performance can also be used in 'what-if' scenarios, process planning and resource allocation.

\section{CONCLUSION}

The aim of this research paper was to propose an understanding of unpredictable behaviour by applying environment performance indicators in a real environment. As seen in the literature review section, this can be done through business process simulation modelling. The purpose of the simulation model will be to answer 'what-if' scenarios and to represent a real environment. A real environment requires environment performance indicators such as environmental conditions and the impact and pressure it would have on a system. The methodology includes implementing a framework/procedure including a list of instructions on how to design the model. As this research paper has reviewed a few number of studies on the structural format for creating a simulation model, more research needs to be carried out for further clarification. When the simulation model has been created, it should be tested and distilled into a performance analysis. The analysis of performance can then help to produce further models. Due to time constraints, the methodology should be put into practice to distinguish results. Further research directions could include tools and software programs to compare which is best for producing a simulation model that aims to answer the research aim which is to understand unpredictable behaviour by the application of environment performance indicators in a real environment. Nevertheless, this research paper has outlined the need for research to be undertaken in this area. The findings will be beneficial for senior management as well as IT staff to better understand the business process model.

\section{REFERENCES}

[1] Ackoff, R.L (1999). Re-Creating the Corporation: A Design of Organizations for the 21st Century. Oxford University Press.
[2] Adamides et al, (2006). A knowledge centred framework for collaborative business process modelling. Business Process Management Journal. 12 (5), p557 - 575.

[3] Aguilar-Savén, R.S. (2003). Business process modelling: Review and framework. International Journal of Production Economics. 90, p129-149.

[4] Box and Taio (1973) G.E.P. Box, G.C. Taio Bayesian Inference in Statistical Analysis, Addison-Wesley, Reading, MA (1973)

[5] Bryman, et al, 2011. Business Research Methods. 3rd edition. Oxford: Oxford University Press.

[6] Collis et al, (2003). Business Research. 2nd ed. Palgrave Macmillan.

[7] Dantes. (2006). Environmental Performance Indicators, EPI. Available: http://www.dantes.info/Tools\&Methods/Environmentalin formation/enviro_info_spi_epi.htmlLast accessed 13th May 2016.

[8] Giddens A. The constitution of society: Outline of the theory of structuration. Cambridge: Polity Press; 1984.

[9] Kettinger et al, (1997), "Business process change: a study of methodologies, techniques and tools", MIS Quarterly, Vol. 21, pp. 55-80.

[10] Kruger, D. J. (2003). Integrating quantitative and qualitative methods in community research. The Community Psychologist, 36, 18-19.

[11] Melão et al. A conceptual framework for understanding business processes and business process modelling. Information Systems Journal. 10 (2), p105-129.

[12] Neville, C. (2007). Introduction to Research and Research Methods. Available: http://www.pasadena.edu/files/syllabi/stvillanueva_3767 0.pdf. Last accessed 11th May 2016.

[13] O'Neill, R. (2006). Advantages and disadvantages of quantitative data analysis. Available: http://archive.learnhigher.ac.uk/analysethis/mobile/main/ quantitative1.html. Last accessed 12th May 2016.

[14] Rajala et al, (1996). A framework for customer oriented business process modelling. Computer Integrated Manufacturing Systems. 9 (3), p127-135. 